\title{
Synthesis and Characterisation of Cobalt(III) Chelates of Symmetrical 3-Nitro-1, 5-diarylformazans
}

\author{
NITIKA, SANJEEV KUMAR and RAJEEV SHARMA \\ Department of Chemistry, Multani Mal Modi College, Patiala-147001, India \\ nitisingla1357@gmail.com
}

Received 9 December 2013 / Accepted 2 January 2014

\begin{abstract}
The synthesis and characterisation of cobalt(III) chelates of 3-nitroformazans have been described. These chelates have been characterized as tris chelates on the basis of elemental analysis, IR and ${ }^{1} \mathrm{H}$ NMR studies. These studies reveal that the coordination of the cobalt(III) to the ligands occurs through the nitrogen atoms 1 and 5 of the formazyl group and that the $\mathrm{NO}_{2}$ group of the ligand does not take part in coordination. The structure of these chelates contains three symmetric six membered $\mathrm{CN}_{4} \mathrm{Co}$ rings.
\end{abstract}

Keywords. Formazans, Chelates, Coordination, Cobalt, Symmetrical

\section{Introduction}

Transition metal complexes of polyazo ligands have attracted considerable attention in the last few years. Despite the fact that synthetic route to formazans were well developed over a half century ago $^{1}$ and there are now over one thousand reported derivatives ${ }^{2}$, the coordination chemistry of formazans has not received much attention. Publications describing transition metal-formazans complexes have appeared sporadically since the $1940^{3-12}$. There have been almost no systematic investigation ${ }^{13-16}$. Also there is little known about the structure of metal complexes of 3-nitroformazans ${ }^{17-20}$, although the metal-binding properties of these ligands are associated with colour changes, and as a result found applications as dyes or as metal-sensing agents ${ }^{21-25}$.

3-Nitroformazans $(3 \mathrm{NFz})^{26}$, prepared by reacting diazotized aromatic amine with nitromethane in cold are known to be intramolecularly hydrogen bonded. Their IR and ${ }^{1} \mathrm{H}$ NMR spectra indicate that the $\mathrm{NH}$ group is strongly chelated and a symmetrical structure (I), out of many geometric isomers has been suggested ${ }^{17}$ and confirmed on the basis of $\mathrm{x}$-ray studies ${ }^{27,28}$.<smiles>[N][N+]1=NC([N+](=O)[O-])=NN([AlH2])N1</smiles> 
There is a considerable number of references available in literature concerning bis chelates of formazans with cobalt(II) but tris chelates of formazans with cobalt(III) are rarely reported ${ }^{29}$. Thus, the method given here in the experimental section for the synthesis of cobalt(III) chelates of 3-nitro-1, 5-diarylformazans is being reported for the first time.<smiles>O=[N+]1O[Y10](=[W])N([Al])N=C1N=C=N[Al]</smiles>

(II)

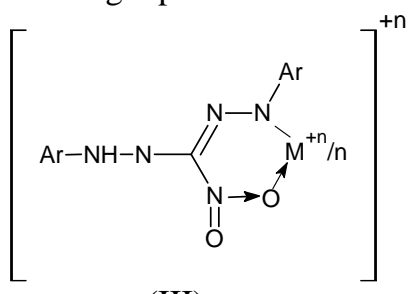

(III)

The symmetrical 3-nitro-1, 5 diarylformazans are the versatile complex forming agents as their coordination to cobalt(III) may occur in number of ways, because of the large number of coordination centres in them. The chelation of (I) with cobalt(III) may occur through, (i) one of the oxygen atoms of the nitro group and one of the four nitrogens of the formazans group giving structures (II) and (III), (ii) nitrogens 1 and 4 of the formazans group giving structures (IVa) or (IVb) having cis or trans geometry respectively or (iii) nitrogen 1 and 5 of the formazan group giving symmetrical six membered chelates ring structure (V).

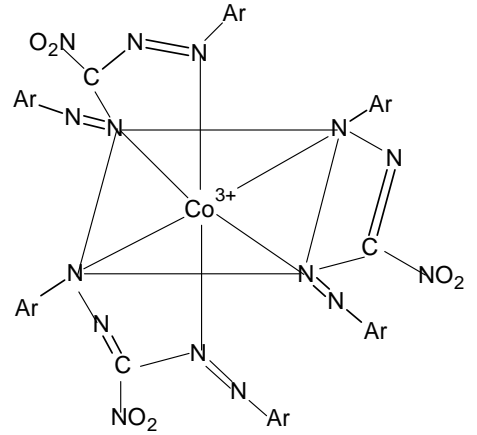

(IV a)

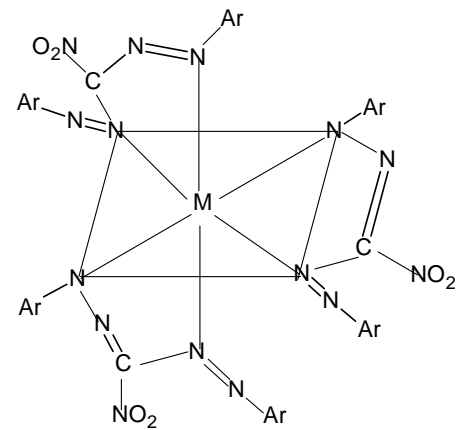

$(\mathrm{IV} b)$

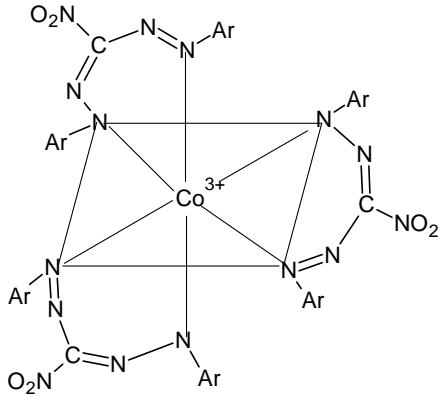

(V)

Ar = phenyl, $o$-tolyl, $p$-tolyl, $o$-anisyl, $p$-anisyl, $p$-bromophenyl, $p$-chloropheyl, $p$-phenity

In the present investigation, cobalt(III) chelates of some symmetrical 3-nitroformazans have been synthesized and characterized on the basis of elemental analysis and spectral studies. Also an attempt has been made to establish the site of chelation and ring size in these chelates on the basis of IR and ${ }^{1} \mathrm{H}$ NMR spectral studies. 


\section{Experimental}

The ligands namely 3-nitro-1,5-diphenylformazan, 3-nitro-1,5-di-o-tolylformazan, 3-niro1,5-di-p-tolylformazan, 3-nitro-1,5-di-o-anisylformazan, 3-nitro-1,5-di-p-anisylformazan, 3-nitro-1,5-d-p-phenitylformazan 3-niro-1,5-di-p-chloroformazan and 3-niro-1,5-di-pbromoformazan were prepared by the reported methods ${ }^{17}$.

Preparation of cobalt(III) chelates of 3-nitro-1,5-diarylformazans

A convenient method for the synthesis of pure tris(3-nitro-1,5-diarylformazan) cobalt(III) chelates was the reaction of hexaminecobalt(III) chloride with 3-nitro-1,5-diarylformazans. The details of which are given below:

An aqueous solution of hexaminecobalt(III)chloride (500 $\mathrm{mg}$ in minimum quantity of distilled water), silver nitrate $(953.27 \mathrm{mg})$ and sodium nitrate $(2.5 \mathrm{~g})$ were heated on a hot plate for 20-25 minutes to precipitate silver chloride completely. The solution was filtered and the filterate was added to the methanolic solution of ligand (500 $\mathrm{mg}$ in $50 \mathrm{~mL}$ ).

The resulting solution was reluxed for 18-20 h and the reddish brown crystals thus formed were filtered and thoroughly washed with distilled water. The complex thus obtained was again purified by column chromatography using silica column. The dark reddish brown band of the complex, which eluted out first, using benzene as eluent, was concentrated and recrystallized twice from chloroform- hexane. The impurities adhering on the top of the column moved only with methanol. These were of gummy nature and could not be crystallised. However, these unidentified products showed a negative test for cobalt.

\section{Estimation of cobalt}

Cobalt in these chelates was estimated spectrophotometrically with phenylazobenzaldoxime ${ }^{30}$ and was occasionally re-checked by EDTA titration method ${ }^{31}$ using xylenol orange indicator.

\section{Estimation of nitrogen}

Nitrogen in these chelates was estimated by Kjeldhal's method ${ }^{32}$.

\section{Spectral studies}

The IR of these chelates were recorded on M-80 IR spectrophotometer. The results are summarized in Table 2. The ${ }^{1} \mathrm{H}$ NMR spectra of these chelates were recorded on $300 \mathrm{MHz}$ Brucker Avance spectrophotometer and the results are summarized as follows.

\section{Tris(3-nitro-1,5-diphenylformazanato)cobalt(III)}

Molecular Formula: $\mathrm{C}_{30} \mathrm{H}_{30} \mathrm{~N}_{15} \mathrm{O}_{6} \mathrm{Co}$; Elemental analysis (\%) Found (Calcd): N- 23.88 (24.30), Co- 6.72 (6.80); IR (KBr pellets, $\left.\mathrm{cm}^{-1}\right): 1560\left(\mathrm{NO}_{2}\right.$, asym), 1490 (N=C-N, asym), $1410(\mathrm{~N}=\mathrm{N}, \mathrm{sym}), 1370(\mathrm{~N}=\mathrm{C}-\mathrm{N}, \mathrm{sym}), 1270\left(\mathrm{NO}_{2}, \mathrm{sym}\right), 840\left(\mathrm{C}-\mathrm{N}\right.$ of $\left.\mathrm{C}-\mathrm{NO}_{2}\right) ;{ }^{1} \mathrm{H}$ NMR $\left(\mathrm{CDCl}_{3}\right):$ 7.25- 7.45(m, aromatic).

\section{Tris(3-nitro-1,5-di-o-tolylformazanato)cobalt(III)}

Molecular Formula: $\mathrm{C}_{45} \mathrm{H}_{42} \mathrm{~N}_{15} \mathrm{O}_{6} \mathrm{Co}$; Elemental analysis (\%) Found (Calcd): N- 21.73 (22.19), Co- 6.05(6.20); IR (KBr pellets, $\left.\mathrm{cm}^{-1}\right)$ : 1565 ( $\mathrm{NO}_{2}$, asym), $1510(\mathrm{~N}=\mathrm{C}-\mathrm{N}$, asym), $1410(\mathrm{~N}=\mathrm{N}, \mathrm{sym}), 1375(\mathrm{~N}=\mathrm{C}-\mathrm{N}, \mathrm{sym}), 1270\left(\mathrm{NO}_{2}\right.$, sym), $840\left(\mathrm{C}-\mathrm{N}\right.$ of $\left.\mathrm{C}-\mathrm{NO}_{2}\right) ;{ }^{1} \mathrm{H}$ NMR $\left(\mathrm{CDCl}_{3}\right)$ : 2.36(s, $\left.-\mathrm{CH}_{3}\right), 7.1-7.6(\mathrm{~m}$, aromatic).

\section{Tris(3-nitro-1,5- p-tolylformazanato)cobalt(III)}

Molecular Formula: $\mathrm{C}_{45} \mathrm{H}_{42} \mathrm{~N}_{15} \mathrm{O}_{6} \mathrm{Co}$; Elemental analysis (\%) Found (Calcd): N- 21.98 (22.19), Co- 6.08(6.20); IR (KBr pellets, $\left.\mathrm{cm}^{-1}\right)$ : 1565 ( $\mathrm{NO}_{2}$, asym), 1507 (N=C-N, asym), $1405(\mathrm{~N}=\mathrm{N}, \mathrm{sym}), 1365$ (N=C-N, sym), $1270\left(\mathrm{NO}_{2}\right.$, sym), $1130(\mathrm{~N}-\mathrm{N}-\mathrm{Ar}), 830\left(\mathrm{C}-\mathrm{N}\right.$ of $\left.\mathrm{C}-\mathrm{NO}_{2}\right)$; ${ }^{1} \mathrm{H} \mathrm{NMR}\left(\mathrm{CDCl}_{3}\right)$ : 2.36(s, $\left.-\mathrm{CH}_{3}\right)$, 6.8-7.46(m, aromatic). 


\section{Tris(3-nitro-1,5-di-o-anisylformazanato)cobalt(III)}

Molecular Formula: $\mathrm{C}_{45} \mathrm{H}_{42} \mathrm{~N}_{15} \mathrm{O}_{12} \mathrm{Co}$; Elemental analysis (\%) Found (Calcd): N- 19.33 (20.13), Co- 4.32(4.40); IR (KBr pellets, $\left.\mathrm{cm}^{-1}\right)$ : $1520\left(\mathrm{NO}_{2}\right.$, asym), 1480 ( $\mathrm{N}=\mathrm{C}-\mathrm{N}$, asym), $1405\left(\mathrm{~N}=\mathrm{N}\right.$, sym), $1375\left(\mathrm{~N}=\mathrm{C}-\mathrm{N}\right.$, sym), $1265\left(\mathrm{NO}_{2}, \mathrm{sym}\right), 1230(\mathrm{~N}-\mathrm{N}-\mathrm{Ar}), 830$ (C-N of $\left.\mathrm{C}-\mathrm{NO}_{2}\right) ;{ }^{1} \mathrm{H}$ NMR $\left(\mathrm{CDCl}_{3}\right): 4.00\left(\mathrm{~s},-\mathrm{OCH}_{3}\right), 6.82-7.75$ (m, aromatic).

\section{Tris(3-nitro-1,5-di-p-anisylformazanato)cobalt(III)}

Molecular Formula: $\mathrm{C}_{45} \mathrm{H}_{42} \mathrm{~N}_{15} \mathrm{O}_{12} \mathrm{Co}$; Elemental analysis (\%) Found (Calcd): N- 19.38 (20.13), Co- 4.29(4.40); IR (KBr pellets, $\left.\mathrm{cm}^{-1}\right): 1560\left(\mathrm{NO}_{2}\right.$, asym), $1500(\mathrm{~N}=\mathrm{C}-\mathrm{N}$, asym), $1405(\mathrm{~N}=\mathrm{N}, \mathrm{sym}), 1370(\mathrm{~N}=\mathrm{C}-\mathrm{N}, \mathrm{sym}), 1260\left(\mathrm{NO}_{2}\right.$, sym), $1220(\mathrm{~N}-\mathrm{N}-\mathrm{Ar}), 840$ (C-N of C$\left.\mathrm{NO}_{2}\right) ;{ }^{1} \mathrm{H} \mathrm{NMR}\left(\mathrm{CDCl}_{3}\right): 3.87\left(\mathrm{~s},-\mathrm{OCH}_{3}\right), 6.82-7.76(\mathrm{~m}$, aromatic).

\section{Tris(3-nitro-1,5-di-p-bromophenylformazanato)cobalt(III)}

Molecular Formula: $\mathrm{C}_{39} \mathrm{H}_{24} \mathrm{~N}_{15} \mathrm{O}_{6} \mathrm{Br}_{6} \mathrm{Co}$; Elemental analysis (\%) Found (Calcd): N- 15.12 (15.70), Co- 4.00(4.41); IR (KBr pellets, $\left.\mathrm{cm}^{-1}\right)$ : $1550\left(\mathrm{NO}_{2}\right.$, asym), $1480(\mathrm{~N}=\mathrm{C}-\mathrm{N}$, asym), $1400(\mathrm{~N}=\mathrm{N}, \mathrm{sym}), 1380(\mathrm{~N}=\mathrm{C}-\mathrm{N}, \mathrm{sym}), 1285\left(\mathrm{NO}_{2}, \mathrm{sym}\right), 830\left(\mathrm{C}-\mathrm{N}\right.$ of $\left.\mathrm{C}-\mathrm{NO}_{2}\right) ;{ }^{1} \mathrm{H}$ NMR $\left(\mathrm{CDCl}_{3}\right):$ 7.25-7.45(m, aromatic).

\section{Tris(3-nitro-1,5-di- p-chlorophenylformazanato)cobalt(III)}

Molecular Formula: $\mathrm{C}_{39} \mathrm{H}_{24} \mathrm{~N}_{15} \mathrm{O}_{6} \mathrm{Cl}_{6} \mathrm{Co}$; Elemental analysis (\%) Found (Calcd): N- 18.12 (19.62), Co- 5.28(5.51) ); IR (KBr pellets, $\left.\mathrm{cm}^{-1}\right): 1540\left(\mathrm{NO}_{2}\right.$, asym), 1480 (N=C-N, asym), $1410(\mathrm{~N}=\mathrm{N}, \mathrm{sym}), 1385(\mathrm{~N}=\mathrm{C}-\mathrm{N}, \mathrm{sym}), 1275\left(\mathrm{NO}_{2}, \mathrm{sym}\right), 820\left(\mathrm{C}-\mathrm{N}\right.$ of $\left.\mathrm{C}-\mathrm{NO}_{2}\right) ;{ }^{1} \mathrm{H}$ NMR $\left(\mathrm{CDCl}_{3}\right):$ 7.25-7.75(m, aromatic).

\section{Tris(3-nitro-1,5-di-p-phenitylformazanato)cobalt(III)}

Molecular Formula: $\mathrm{C}_{51} \mathrm{H}_{54} \mathrm{~N}_{15} \mathrm{O}_{12} \mathrm{Co}$, Elemental analysis (\%) Found (Calcd): N-18.03(18.63), Co-5.08(5.23); IR (KBr pellets, $\left.\mathrm{cm}^{-1}\right)$ : 1520 ( $\mathrm{NO}_{2}$, asym), $1470(\mathrm{~N}=\mathrm{C}-\mathrm{N}$, asym), 1405 (N=N, sym), $1380\left(\mathrm{~N}=\mathrm{C}-\mathrm{N}\right.$, sym), $1265\left(\mathrm{NO}_{2}\right.$, sym), $1240(\mathrm{~N}-\mathrm{N}-\mathrm{Ar}), 845\left(\mathrm{C}-\mathrm{N}\right.$ of $\left.\mathrm{C}-\mathrm{NO}_{2}\right) ;{ }^{1} \mathrm{H}$ NMR $\left(\mathrm{CDCl}_{3}\right): 1.58-1.66$ (t, $\left.-\mathrm{OCH}_{2} \mathrm{CH}_{3}\right), 3.74-3.91\left(\mathrm{q},-\mathrm{OCH}_{2} \mathrm{CH}_{3}\right), 7.28-7.68(\mathrm{~m}$, aromatic).

\section{Results and Discussion}

The chemical analysis of these chelates show that they have 1:3 stoichiometry with the composition $\mathrm{Co}(\mathrm{L})_{3}$ (where $L$-formazanato anion) and thus are tris chelates. The disappearance of $v_{N H}$ in their IR spectra which was found to be present in the corresponding ligands in the range $3200-2900 \mathrm{~cm}^{-1}$, absence of $\mathrm{NH}$ signal in their ${ }^{1} \mathrm{H}$ NMR spectra which was present in the corresponding ligands between 14-15 ppm from TMS in $\mathrm{CDCl}_{3}$, non appearance of new bands characteristic of metal-nitrito type of linkage

$$
\left(\begin{array}{c}
-\mathrm{N}-\mathrm{O} \rightarrow \mathrm{M} \\
\mathrm{O}
\end{array}\right) \text { at } 1360 \mathrm{~cm}^{-1} \text { and } 1110-1050 \mathrm{~cm}^{-1} \text { and }
$$

no appreciable ${ }^{33-36}$ change in the frequencies of vibrations of nitro groups as compared to those of corresponding ligands indicate that these chelates are formed by the substitution of imine hydrogen atom of formazan ring by cobalt(III), there by ruling out the possibility of structure (II) and (III).

The $v_{N=C-N}(\operatorname{asym}), v_{N=N}(\mathrm{sym}), v_{N=C-N}(\mathrm{sym})$ and $v_{N-N-A r}$ stretching frequencies of tris(3NFz) Co(III) chelates appear in the range $1480-1450 \mathrm{~cm}^{-1}, 1430-1380 \mathrm{~cm}^{-1}, 1350-1330 \mathrm{~cm}^{-1}$ and 1180 $\mathrm{cm}^{-1}$ respectively. The corresponding group frequencies of free ligands also appear in the same ranges. The distinction between two structure IV and V could be made only by ${ }^{1} \mathrm{H}$ NMR studies.

In case of trans form IVb is the geometry of these chelates all the three unsymmetrical chelate rings will be magnetically non-equivalent and therefore we should except six such signals for the six chemically indentical magnetically non-equivalent substituents on the aryl groups. 
In the case, the tris (3NFz)Co(III) chelates have five membered ring having cis geometry (Iva), then there should be separate ${ }^{1} \mathrm{H}$ NMR signals for the two chemically identical but magnetically non-equivalent substituents on the two aryl groups of a chelate ring.

The tris (3-nitroformazanato) colbat(III) chelates exists only in one isomeric form as only a single spot is observed on TLC plate for each complex. The ${ }^{1} \mathrm{H}$ NMR of these tris chelates also show a single signal for the chemically equivalent substituents on the aryl groups.

The ${ }^{1} \mathrm{H}$ NMR spectrum of tris (3-nitro-1,5-di-p-anisylformazanato)Co(III) showed only a single $-\mathrm{OCH}_{3}$ signal at $3.87 \mathrm{ppm}$ from TMS in $\mathrm{CDCl}_{3}$. Also a single $-\mathrm{OCH}_{3}$ signal at $4.00 \mathrm{ppm}$ from TMS in $\mathrm{CDCl}_{3}$ was observed in ${ }^{1} \mathrm{H}$ NMR spectrum of tris (3-nitro,1,5-di-oanisylformazanato)Co(III). Similarly the ${ }^{1} \mathrm{H}$ NMR of tris (3-nitro-1,5-di-p-tolylformazanato) $\mathrm{Co}$ (III) showed a single $-\mathrm{CH}_{3}$ signal at $2.36 \mathrm{ppm}$ from TMS and only a single $-\mathrm{CH}_{3}$ signal was observed at $2.36 \mathrm{ppm}$ from TMS in the ${ }^{1} \mathrm{H}$ NMR spectrum of tris(3-nitro-1,5-di-otolylformazanato) cobalt(III). The ${ }^{1} \mathrm{H}$ NMR signal due to aromatic protons in all the tris (3$\mathrm{NFz}$ )Cobalt(III) chelates appear as a multiplet in the range 6.00-8.00 ppm from TMS in $\mathrm{CDCl}_{3}$.

Thus, the ${ }^{1} \mathrm{H}$ NMR data of tris(3NFz)cobalt(III) chelates suggest that these chelates contain three magnetically equivalent symmetric six membered chelate rings. The above results establishing the presence of symmetric six memebered chelates rings in tris(3NFz) cobalt(III) chelates is further supported by the fact that in the ${ }^{1} \mathrm{H}$ NMR spectrum of tris(3nitro-1,5-di-p-phenitylformazanato)Co(III) only one triplet (1:2:1) due to $-\mathrm{CH}_{3}$ centered at 3.84 and only one quartet (1:3:3:1) due to $-\mathrm{OCH}_{2}$ centered at $1.62 \mathrm{ppm}$ from $\mathrm{TMS}$ in $\mathrm{CDCl}_{3}$ due to $p-\mathrm{OCH}_{2} \mathrm{CH}_{3}$ substiutuent was observed.

The ${ }^{1} \mathrm{H}$ NMR of tris(3-nitro-1,5-p-phenitylformazanato)cobalt(III) chelate showing only one triplet due to $-\mathrm{CH}_{3}$ and one quartet due to $-\mathrm{OCH}_{2}$ of $p-\mathrm{OCH}_{2} \mathrm{CH}_{3}$ substituent confirms that these chelates have a symmetrical six membered chelate ring structure (V).

\section{Conclusion}

From the above results and discussion, it is inferred that:

i) The cobalt(III) chelates of 3-nitro-1,5-diarylformazans have stoichiometry of 1:3 and are neutral and thus haracterized as tris chelates formed cobalt(III).

ii) The nitro group of 3-nitro-1,5-diarylformazans do not participate in coordination.

iii) All the tris(3-nitro-1,5-diarylformazanato)cobalt(III) chelates, synthesized and reported here have symmetrical six membered chelate ring structure, $\mathrm{V}$.

\section{References}

1. Nineham A W, Chem Rev., 1955, 55(2), 355-363; DOI:10.1021/cr50002a004

2. Cunningham C W, Burns G R and Mckee V, J Chem Soc Perkin Trans., 1989, 2, 1429-1436; DOI:10.1039/P29890001429

3. Hunter L and Roberts C B, J Chem Soc., 1941, 823.

4. $\quad$ Irving H, Gill J B and Cross W R, J Chem Soc., 1960, 2087.

5. Jameson G B, Muster A, Robinson S D, Wingfield J N and Ibers J A, Inorg Chem., 1981, 20(8), 2448-2456; DOI:10.1021/ic50222a017

6. $\quad$ Gok Y and Senturk H B, Dyes Pigments, 1991, 15(4), 279-287;

DOI:10.1016/0143-7208(91)80013-Y

7. $\quad$ Yuzhen Z and Dongzhi L, Dyes Pigments, 1995, 29(1), 57-63; DOI:10.1016/0143-7208(95)00031-A

8. Szymczyk M, El-Shafei A and Freeman H S, Dyes Pigments, 2007, 72(1), 8-15; DOI:10.1016/j.dyepig.2005.07.009 
9. Siedle A R and Pignolet L H, Inorg Chem., 1980, 19(7), 2052-2056; DOI:10.1021/ic50209a043

10. Brown D A, Bogge H, Lipunova G N, Muller A, Plass W and Walsh K G, Inorg Chim Acta, 1998, 280(1-2), 30-38; DOI:10.1016/S0020-1693(98)00050-4

11. Gilroy J B, Ferguson M J, McDonald R and Hicks R G, Inorg Chimica Acta, 2008, 361(12-13), 3388-3393; DOI:10.1016/j.ica.2008.02.005

12. Gilroy J B, Patrick B O, McDonald R and Hicks R G, Inorg Chem., 2008, 47(4), 1287-1294; DOI:10.1021/ic7019846

13. Kawamura Y, Ohyanishiguchi H, Yamauchi J and Deguchi Y, Bull Chem Soc Jpn., 1984, 57, 1441.

14. Kawamura Y, Deguchi Y, Yamauchi J and Ohyanishiguchi H, Bull Chem. Soc. Jpn., 1988, 61(1), 181-186.

15. Kawamura Y, Yamauchi J and Ohyanishiguchi H, Chem Lett., 1990, 19(9), 16191622; DOI:10.1246/cl.1990.1619

16. Kawamura Y, Yamauchi J and Ohyanishiguchi H, Bull Chem Soc Jpn., 1993, 66(12), 3593-3599; DOI:10.1246/bcsj.66.3593

17. Kalia K C and Kumar A, Indian J Chem., 1978 , 16A, 52.

18. Kalia K C, Kumar A, Singla M and Kaur J, Indian J Chem., 1981, 20A, 610.

19. Sharma R and Kalia K C, Indian J Chem., 1995, 34A, 915.

20. Sharma R and Devgan M and Kalia K C, Indian J Chem., 1996, 35A, 63.

21. Hoshino H, Nakano K and Yotsuyanagi T, J Chromatogr., 1990, 515, 603-610.

22. Szymczyk M, Czajkowski W and Stolarski R, Dyes Pigments, 1999, 42(3), 227-235; DOI:10.1016/S0143-7208(99)00033-9

23. Czajkowski W, Stolarski R, Szymezyk M and Wrzeszez G, Dyes Pigments, 2000, 47(1-2), 143-149; DOI:10.1016/S0143-7208(00)00071-1

24. Ostrovskaya V M, Reshetnyak E A, Nikitina N A, Panteleimonov A V and Kholin Y Y, J Anal Chem., 2004, 59, 995-1001.

25. Takahashi T, Takehara Y and Hoshino H, Bull Chem Soc Jpn., 2007, 80(5), 910-915; DOI:10.1246/bcsj.80.910

26. Tarbell D S, Todd C W, Paulson M C, Lindstorm E G and Wsstarch V P, J Am Chem Soc., 1948, 70(4), 1381-1385; DOI:10.1021/ja01184a027

27. Dijkstra E, Hutton A T, Irving H M N H and Nassimbeni L R, Tet Lett., 1981, 22(40), 4037-4040; DOI:10.1016/S0040-4039(01)82058-X

28. Gilory J B, Otieno P O, Ferguson M J, McDonald R and Hicks R G, Inorg Chem., 2008, 47(4), 1279-1286; DOI:10.1021/ic7019445

29. Yassar G and Barri S H, Dyes Pigments, 1991, 15(4), 279-287;

DOI:10.1016/0143-7208(91)80013-Y

30. Kalia K C and Kumar A, Indian J Chem., 197, 14A(7), 545.

31. Steyermark A, Quantitative Organic Micro Analysis, $2^{\text {nd }}$ Edn., (Academic Press, New York, London), 1961, 209.

32. Jaffery G H, Bassett J, Mendham J and Denny R C, Vogel's text book of quantitative Chemical Analysis, $5^{\text {th }}$ Edn., 1989, 302.

33. Goodgame D M L and Hitchman M A, Inorg Chem., 1964, 3(10), 1389-1394; DOI:10.1021/ic50020a010

34. Goodgame D M L and Hitchman M A, Inorg Chem., 1961, 6(3), 813.

35. Sayed L El and Ragsdale R O, Inorg Chem, 1967, 6(9), 1640-1643; DOI:10.1021/ic50055a006

36. Nakamoto K, Infrared and Raman spectra of Inorganic and Coordination Complexes, John Willey, New York, ${ }^{\text {rd }}$ Edn., 1978, 233. 